\title{
Lidar measurement of planetary boundary layer height and comparison with microwave profiling radiometer observation
}

\author{
Z. Wang ${ }^{1,2}$, X. Cao ${ }^{1}$, L. Zhang ${ }^{1}$, J. Notholt ${ }^{2}$, B. Zhou ${ }^{1}$, R. Liu ${ }^{1}$, and B. Zhang ${ }^{1}$ \\ ${ }^{1}$ Key Laboratory for Semi-Arid Climate Change of the Ministry of Education, College of Atmospheric Sciences, \\ Lanzhou University, Lanzhou, 730000, China \\ ${ }^{2}$ Institute of Environmental Physics, University of Bremen, 28334 Bremen, Germany
}

Correspondence to: L. Zhang (zhanglei@1zu.edu.cn)

Received: 18 January 2012 - Published in Atmos. Meas. Tech. Discuss.: 7 February 2012

Revised: 6 July 2012 - Accepted: 18 July 2012 - Published: 14 August 2012

\begin{abstract}
The atmospheric boundary layer height was derived at two locations in the city of Lanzhou (China) and its suburb rural area Yuzhong. The aerosol backscatter lidar measurements were analysed using a wavelet technology and the parcel method was applied to profiling microwave radiometer observations. For a few occasions the average boundary layer height and entrainment zone thickness was derived in convective situations at Yuzhong. Results from selected observation days show that both datasets agree in strong convective situations. However, for weak convective situations the lidar measurements reveal boundary layer heights that are higher compared to the microwave observations, because a decrease of the thermal boundary layer height does not directly lead to a change of aerosols in that altitude layer. Finally, the entrainment zone thicknesses are compared with theoretical predictions, and the results show that the measurements are compatible with theoretical models.
\end{abstract}

\section{Introduction}

The boundary layer height (BLH) is a key parameter in describing the structure of the atmospheric boundary layer (BL), it determines the volume available for pollutant dispersion. Currently, the BLH cannot be measured directly but can be estimated from remote-sensing profile measurements. The lidar remote-sensing instrument is a useful tool to measure properties of the BL and the BLH.

Lidar backscatter profiles represent the vertical distribution of the aerosol concentration in the atmosphere. Gener- ally, most aerosols have their sources at the surface, producing high concentrations in the BL relative to the free atmosphere above. There are usually sharp gradients in aerosol concentration at the BL top, this provides a method to determine the BLH.

Early lidar studies of the BL used visual estimates to determine the BLH, which are quite subjective. Automated approaches have included the use of simple signal threshold values (Boers and Eloranta, 1986), and identifications of the minimum in the vertical gradients of lidar profiles (Flamant et al., 1997) and maximum in variances of lidar signals (Hooper and Eloranta, 1986; Lammert and Boesenberg, 2006). The first of these suffer from the need to define appropriate threshold values, the second approach, the gradient one suffers from the effects of noise and small-scale structure in the lidar profiles. Averaging the backscatter signal can minimise this problem, but inevitably degrades the signal of interest. Steyn et al. (1999) presented an approach that fit an idealised profile to the observed one, another approach widely used is based on the continuous wavelet transform method (Cohn and Angevineet, 2000; Davis et al., 2000; Brooks, 2003; Morille et al., 2007). When the vertical distribution of aerosols in the BL consists of a multi-layer structure the lidar determination of the BLH will be complicated due to the difficulty to determine a true BL top from these aerosols layer tops. The method applied in this article is based on the work of Morille et al. (2007). They use the wavelet transformation and a set of threshold values to search the location of the BL top. One wavelet function is used to detect the particle layer and another for negative gradients in the lidar profile. The BL top is selected as the position where 
the lidar aerosol profile has its strongest negative gradients, however, this position does not always correspond to the $\mathrm{BL}$ top. In our approach, instead of just selecting the maximum negative gradient, multiple positions are selected and then the BL top is determined by assuming the continuity in the evolution of BL top as a function of time.

The entrainment zone thickness is another important parameter of the BL. The entrainment zone is located at the top of the BL and consists of a mixture of air from the BL below and free-troposphere characteristics from above. It is defined as the region with negative buoyancy flux (Stull, 1988). However, various alternative definitions occur in measurements because of different means (Boers and Eloranta, 1986; Nelson et al., 1989; Flamant et al., 1997; Grabon et al., 2010). In this paper, the definition used by Cohn and Angevineet (2000) is applied, whose algorithm searches for the locations of percentiles of the BL top. The results are compared with that from theoretical models.

The following Sect. 2 introduces the sites and measurements. The method is described in Sect. 3, results are shown in Sect. 4, and Sect. 5 gives the summary and discussion.

\section{Observation sites and instrumentation}

The data used in this paper have been recorded at the SemiArid Climate Observatory and Laboratory of Lanzhou University (SACOL) including two sites located at the suburb rural area of Lanzhou - Yuzhong (SACOL-Main, $35.950^{\circ} \mathrm{N}$, $104.133^{\circ} \mathrm{E}, 1965.8 \mathrm{~m}$ ) and the city of Lanzhou (SACOLLanzhou, $36.054^{\circ} \mathrm{N}, 103.859^{\circ} \mathrm{E}, 1525.0 \mathrm{~m}, 48 \mathrm{~km}$ far from SACOL-Main), respectively. All the instruments used are operated at SACOL-Main except for the lidar (CE370-2) at SACOL-Lanzhou.

The micro-pulse lidar (CE370-2) includes a co-axial system with a $20 \mathrm{~cm}$ diameter receiving telescope and a Qswitched frequency doubled Nd: YAG laser operated at $532 \mathrm{~nm}$. The pulse repetition frequency is configured to $4.7 \mathrm{kHz}$. It is capable of obtaining the aerosol vertical profiles from the ground up to $30 \mathrm{~km}$ altitude with an altitude resolution of $15 \mathrm{~m}$. The lidar (MPL-4) uses an Nd:YLF pulsed laser diode, operating at $527 \mathrm{~nm}$. The aerosol and cloud measurements are recorded with a spatial resolution of $75 \mathrm{~m}$ and at a temporal resolution of $1 \mathrm{~min}$.

The microwave radiometer (TP/WVP-3000) is a passive remote-sensing instrument. It has two systems for measurements of the temperature and relative humidity profiles. It works at $22-60 \mathrm{GHz}$, where the spectral region $22-30 \mathrm{GHz}$ is used for the water vapour profile and the $51-59 \mathrm{GHz}$ region to determine the temperature profile. The radiometer allow obtaining the vertical profiles of temperature, water vapour and liquid water from the ground up to $10 \mathrm{~km}$ altitude with a time resolution of $1 \mathrm{~min}$. Below the $1 \mathrm{~km}$ height, the altitude resolution is $0.1 \mathrm{~km}$, above $0.25 \mathrm{~km}$.

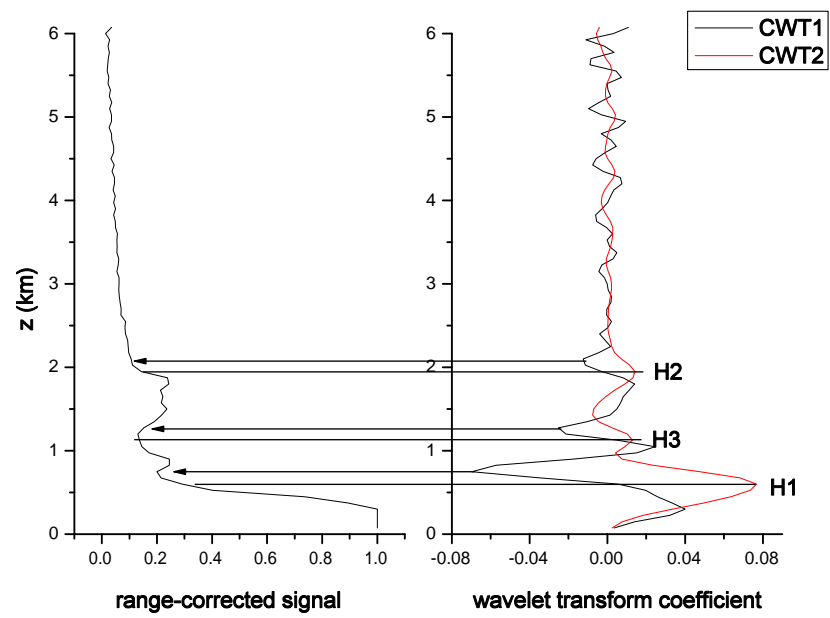

Fig. 1. Illustration for wavelet transformation, $\mathrm{CWT}_{1}$ is used to detect the particle layer, and $\mathrm{CWT}_{2}$ is used to follow the negative gradients of lidar profile. The minima of $\mathrm{CWT}_{1}$ corresponding to the base and top of particle layer, are indicated by the arrows. The maxima of $\mathrm{CWT}_{2}$ correspond to the positions of negative gradients, and $H 1, H 2, H 3$ are the first three maxima.

The fluxes of momentum, latent and sensible heat are measured at $3.0 \mathrm{~m}$ altitude with a three-axis sonic anemometer (CSAT3, Campbell) pointing into the prevailing wind direction and an opened path infrared $\mathrm{CO}$ and $\mathrm{HO}$ analyser (LI7500, LI-COR). These signals are logged to a data logger (CR5000, Campbell) at $10 \mathrm{~Hz}$.

\section{Methodology}

\subsection{The detection of the BLH}

The BLH is determined according to the sharp gradient of lidar profile at the top of the BL, however, the sharp gradient also occurs at the top of clouds or advected aerosols layers which, therefore, should also be identified. The continuous wavelet transform (CWT) for each lidar profile is given by

$$
\begin{aligned}
& \operatorname{CWT}_{i}(a, b)=\int_{z_{1}}^{z_{2}} p(z, t) g_{i}\left(\frac{z-b}{a}\right) \frac{1}{\sqrt{a}} \mathrm{~d} z, i=1,2 \\
& g_{1}(t)=\left(1-t^{2}\right) e^{-t^{2} / 2} / \sqrt{2 \pi} \\
& g_{2}(t)=-t e^{-t^{2} / 2} / \sqrt{2 \pi}
\end{aligned}
$$

Where, $p(z, t)$ represents the altitude-corrected backscatter signal. $\mathrm{CWT}_{1}(a, b)$ has its minimum at the top and base of clouds or advected aerosol layers, as mentioned above, and maximum at a position within them where the lidar signal peaks. After first determining potential particle layers, a threshold value "thre1" is applied to exclude the effect of noise fluctuation. Those potential particle layers satisfying the condition $\Delta p=p\left(z_{\text {peak }}, t\right)-p\left(z_{\text {base }}, t\right)>$ thre 1 are 

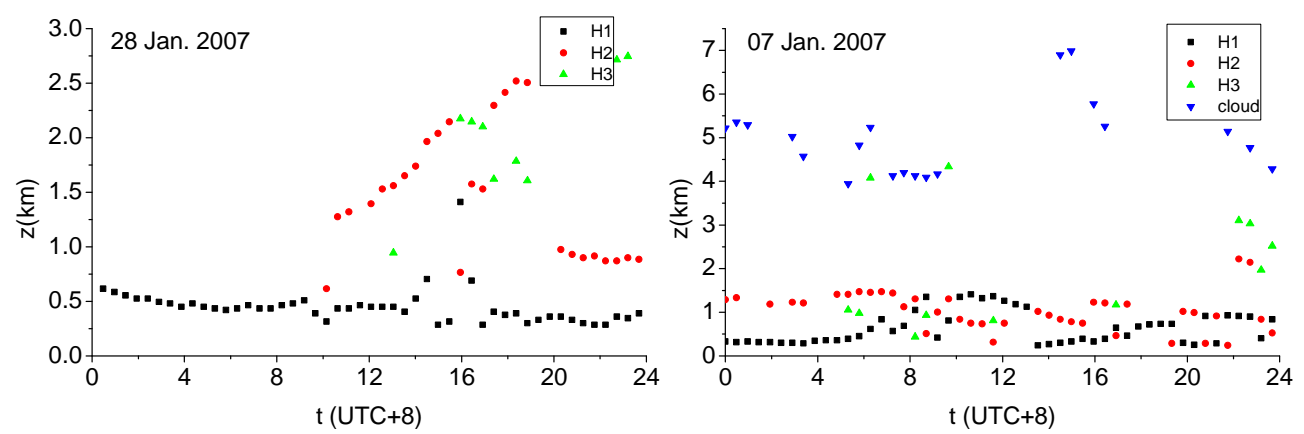

Fig. 2. Temporal evolution of aerosol layer height on two days in January 2007. Each dot represents the average for five minutes measurements. Measurements were taken every $30 \mathrm{~min}$.
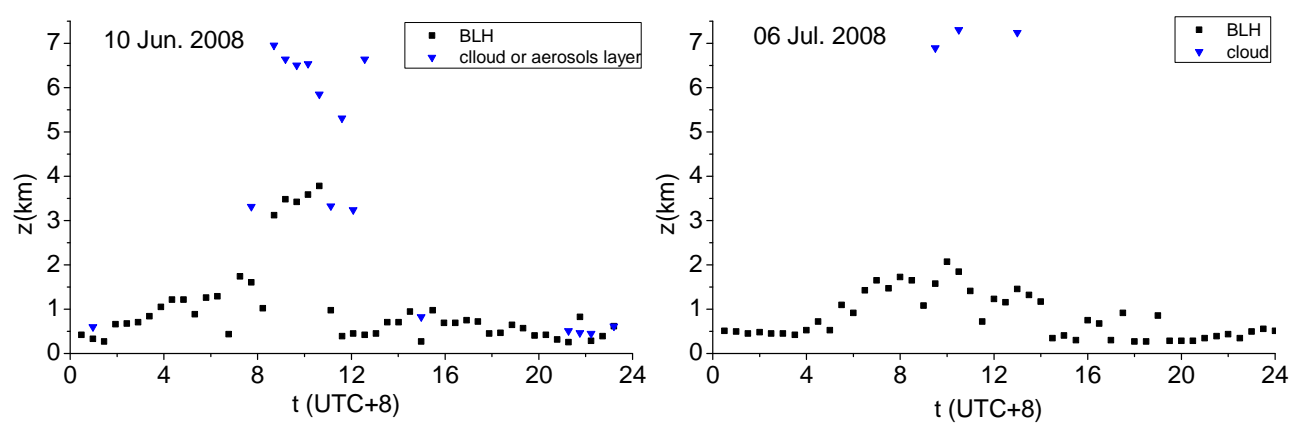

Fig. 3. The diurnal evolution of BLH on two days during summer of 2008. Each dot represents the average for five minutes measurements. Measurements were taken every $30 \mathrm{~min}$.

considered true. The method of detecting the particle layer is the same as used by Morille et al. (2007). They recommend ten times the noise level as threshold value. In our case, a visual estimated value is used to all measurements. Similarly, $\mathrm{CWT}_{2}(a, b)$ has its maximum at the part of lidar profile where the altitude-corrected backscatter signal decreases with height. The working principle of the wavelet transformation is illustrated in Fig. 1. The largest maximum of $\mathrm{CWT}_{2}(a, b)$ often occurs at the top of the BL when both cloud and advected aerosols layer are absent. Currently the following method is applied to retrieve the BLH.

- The first, second and third largest values $(H 1, H 2, H 3)$ are selected as maxima of $\mathrm{CWT}_{2}(a, b)$ except for those corresponding to cloud and advected aerosol layers top. During cloudy situations, only those maxima located under the base of the cloud are considered. The locations of the three maximums likely denote the BL top.

- "oldblh" is defined as the average of five successive BLHs during a time interval directly before the lidar signal. "oldblh" represents the average of the earlier BLHs and is used to characterise the degree to which the positions of current $H 1, H 2$ and $H 3$ depart from the former BL top.
- After that, the analysis continues in the following way:

1. During cloudfree conditions, assuming that there is an advected aerosol layer and all maxima of $\mathrm{CWT}_{2}(a, b)$ are located below the base of this aerosol layer are smaller than zero then the one closest to oldblh between its top and base will be considered as the BL top.

2. If Eq. (1) does not match, there is a cloud or advected aerosol layer and $H 1$ is smaller than a threshold value "thre2". In that case the base of this cloud or aerosol layer will be considered as the $\mathrm{BL}$ top. Only those maxima of $\mathrm{CWT}_{2}(a, b)$ that are larger than this threshold value are considered as corresponding to some features of the boundary structure other than noise fluctuations. In this case there is a cloud or aerosol layer located at the top of the boundary layer (Morille et al., 2007).

3. If Eqs. (1) and (2) do not match, the following functions will be applied,

$r(x)=\min \left(\mathrm{e}^{-\frac{x-c(t)}{\sigma}}, 1\right)$

ratio $=H / H 1$

Where, $c(t)$ represents a range in which the difference between two successive BLHs is acceptable and $\sigma=$ 


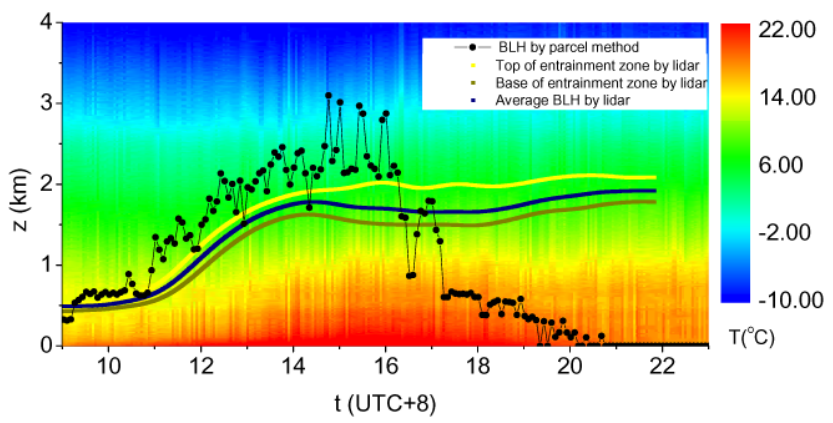

Fig. 4. Comparison between results from lidar and microwave profiling radiometer measurements for 29 July 2007. The dotted line represents the BLH from the microwave profiling radiometer determined by the parcel method and each dot is the average for five minutes measurements.

$c(t) / 5 \ln 2$. The stronger thermal convection is in the BL, where the range, $c(t)$ is larger. Here, we just assume that $c(t)$ increases linearly before 12:00 of local time and then maintain constant after that. $H$ represents the value between $H 2$ and $H 3$ whose altitude is closer to "oldblh". A large $r\left(\mid z_{H 1}-\right.$ oldblh $\left.\mid\right)$ means a larger possibility that the altitude of $H 1$ denotes the true BLH, a large "ratio" means a reverse one. If ratio is larger than $r\left(\mid z_{H 1}-\right.$ oldblh $\left.\mid\right)$, then the location of $H$ will be considered as the BL top, otherwise the location of $H 1$ is accepted. This criterion guarantees the temporal continuity of the development of the BLH. The parameters in the expressions above, vary according to the time resolution of the lidar data; the larger the interval between the two successive records is, the less important it is.

\subsection{Average BLH and entrainment zone thickness}

The entrainment zone thickness can be calculated from the temporal (Wilde et al., 1985; Cohn et al., 2000) or spatial (Flamant et al., 1997) variation of local BLH top. A single lidar profile from MPL-4 represents an average for one minute measurements. The BLH from the single profile denotes the local BLH, so the average BLH and the entrainment zone thickness can be derived from temporal development. The method used here is the same as that proposed by Cohn et al. (2000). First, a cumulative probability distribution (CPD) is calculated from the occurrence of the sequence of the BLH values for $1 \mathrm{~h}$, whose trend has been removed by fitting a second-order polynomial. Second, the value corresponding to $10 \%, 90 \%$ and $50 \%$ of CPD is added to the second-order polynomial to give the base, top of the entrainment zone and the average BLH, respectively. The percentages defining the top and base of entrainment zone are different from those proposed by Wilde et al. (1985) and Cohn et al. (2000). Flamant et al. (1997) proposed an approach to determine these quantities from correlated atmospheric lidar and in situ measurements.

\subsection{Parameterisation theory of entrainment zone thickness}

According to parcel theory, the entrainment zone thickness is related to the kinetic energy and resistance of the air parcel rising (Bores and Eloranta, 1986). It can be written as: $\Delta h \propto \frac{w^{2}}{g \Delta \theta / \theta_{0}}$, where $\Delta h$ is the entrainment zone thickness, $g$ is the gravitational constant, $\Delta \theta$ is the potential temperature change across the entrainment zone, $\theta_{0}$ is the average potential temperature in the $\mathrm{BL}$, and $w$ is the vertical velocity. $w$ is typically characterised by the convective velocity scale defined as: $w_{*}^{3}=\frac{g \overline{\left(w^{\prime} \theta^{\prime}\right)_{\mathrm{s}} h}}{\theta_{0}}$, where $h$ is the average BLH and $\overline{\left(w^{\prime} \theta^{\prime}\right)_{\mathrm{s}}}$ is the kinematic heat flux at the surface. Gryning and Batchvarova (1994) derived another parameterisation based on the turbulent-kinetic-energy equation. It can be written as: $\frac{\Delta h}{h} \propto\left(R i_{\mathrm{E}}\right)^{-1 / 3}$, with $R i_{\mathrm{E}}=\frac{\left(g / \theta_{0} h \Delta \theta\right.}{w_{e}^{2}}$ as the entrainment Richardson number, $w_{e}=\frac{\partial h}{\partial t}-w_{L}$ is the entrainment velocity, and $w_{\mathrm{L}}$ is the large-scale mean vertical velocity, which can be neglected in case of strong convection. In addition, $\frac{\Delta h}{h} \propto\left(\frac{w_{e}}{w_{*}}\right)^{\alpha}$ as proposed by Nelson et al. (1989), where three possible exponents 1.0, 0.5 and 0.25 are suggested. The retrieved entrainment zone thickness is examined through those theories, the kinematic heat flux at the surface is provided by the three-axis sonic anemometer, and the mean potential temperature of the BL and the potential temperature change across the entrainment zone are derived from temperature profiles by the microwave profiling radiometer. For the $\mathrm{BLH}$, the one given by the lidar-MPL is used. However, there may be relatively large errors in the potential temperature change across the entrainment zone due to the limited vertical resolution of the profile data of the profiling radiometer.

\section{Results}

The method described above is applied to lidar measurement at SACOL-Main and SACOL-Lanzhou, respectively. For the site at Lanzhou, only the BLH is derived. But for SACOLMain site, the lidar data have higher time resolution (1 min), so the average BLH and entrainment zone thickness are calculated. At the main site, SACOL-Main the temperature profile is also available from the microwave profiling radiometer, the parcel method described by Holzworth (1964) and Seibert et al. (2000) has been used to derive the BLH from temperature profile. Its basic idea is to follow the dry adiabatic temperature profile starting at the surface and to compare it with the measured temperature profile to find their intersection. This determines the BLH. In the case of the lidar, the BLH is derived from the vertical distribution of aerosols that are indirectly related to the thermal condition in the boundary layer. In the case the aerosol distribution is mainly controlled by turbulence transport in the BL, the aerosol measurements allow us to follow the evolution of the BL. Different instruments measure different aspect of the BL properties, and 

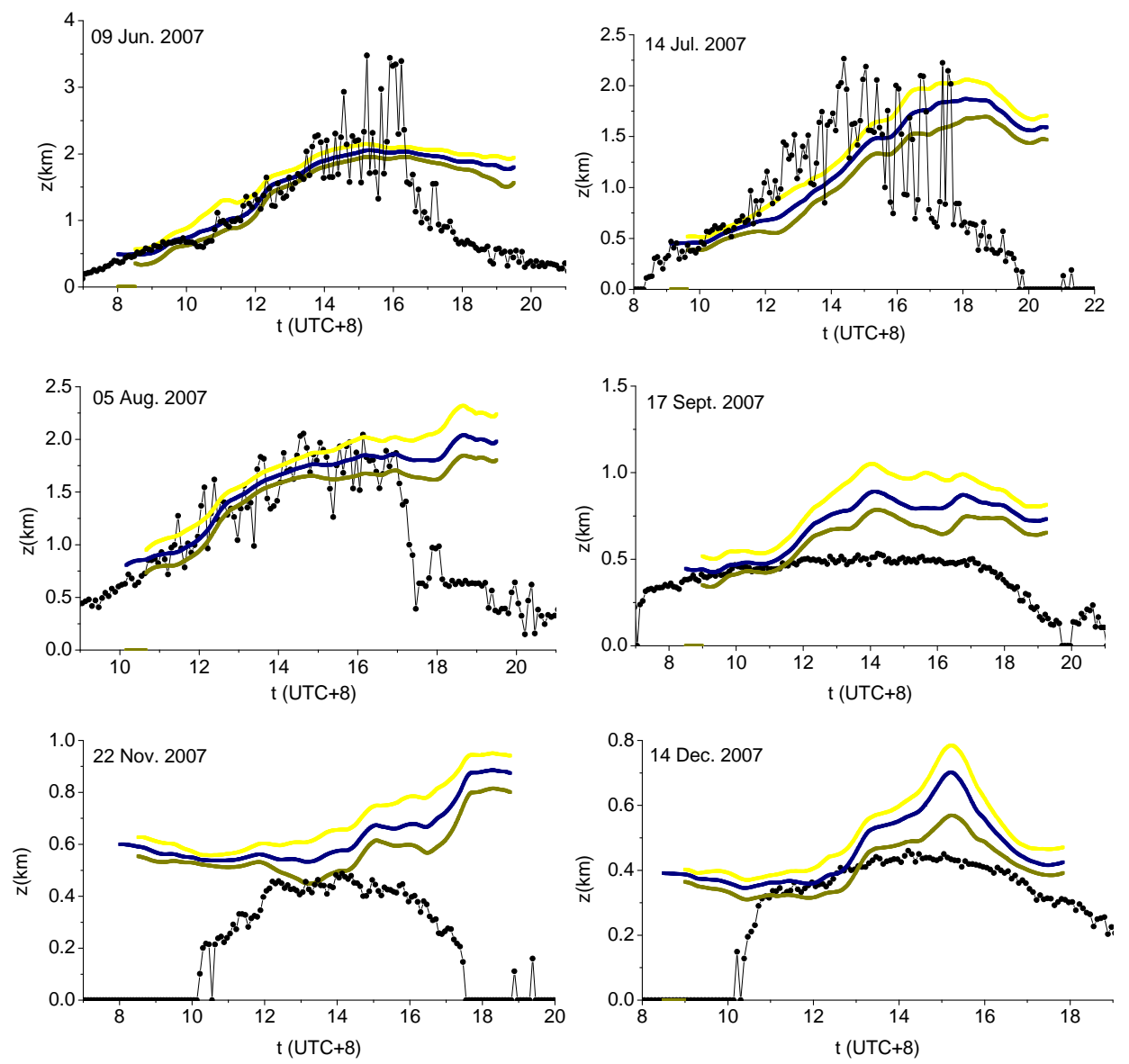

Fig. 5. Comparisons between the BLH from lidar and microwave profiling radiometer for six measurement days in the period of June to December 2007. The contents are the same as Fig. 3, except that temperature measurements are not showed.

result in values for the BLHs which do not necessarily agree with each other. Van Pul (1994) compared the BLH of noon from lidar and radiosondes, and found both agree well. Emeis et al. (2004) compared the BL structures determined by a sodar, by a rass (radio acoustic sounding system) and by a ceilometer. Wiegner et al. (2006) presented a comparison of a comprehensive set of instruments and methodologies. Emeis et al. (2008a) summarised and compared various approaches for determining the BLH from acoustic, optical and electromagnetic remote sensing. In the following, the $\mathrm{BLH}_{\mathrm{aerosol}}$ and $\mathrm{BLH}_{\text {temp }}$ are used to represent the BLH from the aerosol distribution and temperature profile, respectively.

\subsection{The BL in the city of Lanzhou}

Figures 2 and 3 show four cases of lidar-CE370 under nearly fair weather conditions, performed at SACOL-Lanzhou. Lanzhou is located in a valley basin. The basin is elliptical, surrounded by mountains with the Yellow River flowing through the city. The geography and meteorological conditions make it difficult for pollutants to diffuse. The vertical distributions of aerosols in the BL usually show a com- plicated multi-layer structure. Figure 1 shows the evolution of $H 1, H 2$ and $H 3$ to illustrate their different features. On 28 January 2007, only $H 2$ and $H 3$ when larger than $0.15 H 1$ have been shown, and $0.25 H 1$ on 7 January 2007 (Fig. 2). Figure 3 shows the evolution of the $\mathrm{BLH}_{\text {aerosol }}$ for two days in 2008 .

On 28 January 2007 (Fig. 2), the aerosol concentrations for the whole day below $0.5 \mathrm{~km}$ are relatively high compared to the ones above $0.5 \mathrm{~km}$. There is a very strong gradient in the aerosol concentration at the top of the aerosol layer, and $H 1$ mainly denotes its top. After 09:00, the thermal rising of the air-masses produce a second aerosol layer with a weak gradient at its top above the first one, $\mathrm{H} 2$ denotes its top before 16:00. On 10 June 2008 (Fig. 3), from 08:00 to 12:00, there are clouds at $3.0 \mathrm{~km}$ altitude initially which dissipated but then appeared again later. The $\mathrm{BLH}_{\mathrm{aerosol}}$ for the cloudfree conditions are not correct.

In the city of Lanzhou, it is in most cases difficult to determine the reasonable $\mathrm{BLH}_{\text {aerosol }}$ owing to the multi-layer distribution of aerosols. For these cases the method proposed by Haij et al. (2006) or the algorithm developed by Davis et 

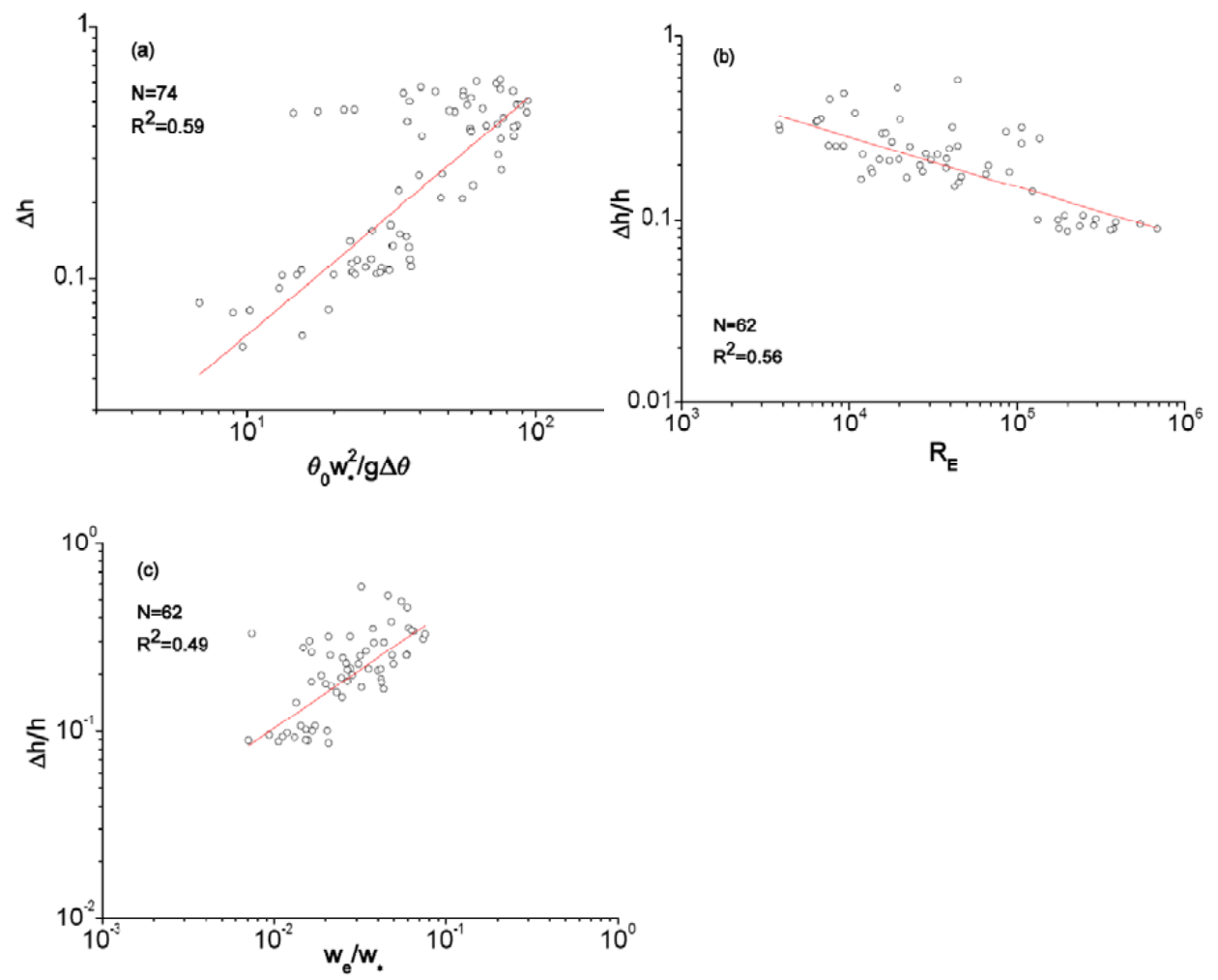

Fig. 6. Comparison of entrainment zone data with theoretical values: (a) entrainment zone thickness, (b) normalised entrainment zone thickness and entrainment Richardson number, (c) normalised entrainment zone thickness and ratio of entrainment velocity and convective velocity scale.

al. (2000) might be more suitable. Both of them determine multiple aerosol layers from each lidar profile.

\subsection{The BL in suburb rural area of Lanzhou - Yuzhong}

Figure 4 shows the results from the lidar-MPL and microwave profiling radiometer measurements on 29 July 2007 at SACOL-Main. Between 11:00 and 16:00 the $\mathrm{BLH}_{\text {aerosol }}$ is about $0.5 \mathrm{~km}$ lower than the $\mathrm{BLH}_{\text {temp }}$ from microwave profiling radiometer. The latter begins to rise rapidly from 11:00 on while the result from the lidar increases more slowly. This delay in the development of aerosol distribution compared to the development of the thermal structure of the boundary layer has been revealed by Emeis and Schafer (2006) and Emeis et al. (2008b) using sodar and ceilometers. After 16:00, the $\mathrm{BLH}_{\text {temp }}$ decreases quickly and disappears at 20:00, but the results from lidar maintain at $2.0 \mathrm{~km}$ altitude. This discrepancy can be assigned to the fact that the $\mathrm{BLH}_{\text {temp }}$ represents an upper limit altitude which the rising thermal air-masses can reach while the $\mathrm{BLH}_{\text {aerosol, }}$, representing the height of the aerosol layer, does not drop immediately as the temperature decreases, since the aerosols concentrations do not dilute when mixing with the surrounding air immediately.

Figure 5 shows results for six measurement days between June and December 2007 at SACOL-Main. In situations with strong convection, the $\mathrm{BLH}_{\text {aerosol }}$ agrees with $\mathrm{BLH}_{\text {temp }}$, such as the examples in June, July and August show. However, in situations with weak convection, the $\mathrm{BLH}_{\text {aerosol }}$ is markedly higher, as shown by the observations in September, November and December. Another feature is the abrupt decline of $\mathrm{BLH}_{\text {temp }}$ in the afternoon, where the $\mathrm{BLH}_{\text {aerosol }}$ maintain its altitude roughly or decreases slowly. The $\mathrm{BLH}_{\text {temp }}$ is mainly determined by the thermal condition in the BL, it can describe the evolution of the convective BL in the morning when thermal turbulence dominates. The $\mathrm{BLH}_{\text {aerosol }}$ does not always follow this development. $\mathrm{BLH}_{\mathrm{aerosol}}$ still denotes the height of aerosol layer formed at night, such as the case of November and December. However, in the afternoon the convective $\mathrm{BL}$ departs into a residual layer and a stable layer, where the $\mathrm{BLH}_{\text {aerosol }}$ likely represent the height of residual layer.

\subsection{Examination of entrainment zone thickness by parameterisation theory}

The entrainment zone thickness is related to the BL and surface properties, such relationship is described by the so-called parameterisation theory, which is used here to check the consistency between the derived quantities and the theory. The method applied in this study to retrieve 
the entrainment zone thickness is likely suitable for situations with strong convection, thus, data from lidar-MPL at SACOL-Main on 14, 16, 22, 23 and 29 July 2007 are used. For each day only results between 10:00 and 18:00 are utilised. In Fig. 6a, the expression fitted according to the parcel theory is $\Delta h=0.0065\left(\frac{w_{*}^{2}}{g \Delta \theta / \theta_{0}}\right)^{0.96}$. However, the result following Boers and Eloranta (1986) is $\Delta h=$ $38.41\left(\frac{w_{*}^{2}}{g \Delta \theta / \theta_{0}}\right)^{0.41}$. Such a difference may arise from a different method that was used in their measurements. Boers and Eloranta (1986) derived the entrainment zone thickness using a scanning lidar, which means the thickness is derived based on variations of the BL top over some horizontal distance. In Fig. 6b, the expression based on the theory proposed by Gryning et al. (1994) is $\frac{\Delta h}{h}=3.38\left(R i_{\mathrm{E}}\right)^{-0.27}$. The result derived by Gryning et al. (1994) is $\frac{\Delta h}{h}=3.3\left(R i_{\mathrm{E}}\right)^{-1 / 3}+0.2$. Both are close to each other except a constant, Gryning et al. (1994) used the lidar of Boers and Eloranta (1986) and in addition to water tank experiment data. In Fig. 6c, the fitted relation is $\frac{\Delta h}{h}=1.8\left(\frac{w_{e}}{w_{*}}\right)^{0.62}$. Although Nelson at al. (1989) suggested three values 1.0, 0.5 and 0.25 for the exponent, their results revealed that the exponent varies with time during a day, and this maybe explain the low correlation coefficient in Fig. 6c.

\section{Conclusions}

The BLH over the city of Lanzhou and its suburb rural area Yuzhong has been obtained using a modified wavelet technology and lidar data. The results reveal the effectiveness of this method for Yuzhong. But our study clearly shows that the method is less effective for Lanzhou city, owing to the multi-layer distribution of aerosols. At Yuzhong, the BLH is also calculated using a measured temperature profile from microwave profiling radiometer. The comparison shows that $\mathrm{BLH}_{\text {aerosol }}$ and $\mathrm{BLH}_{\text {temp }}$ agree with each other under strong convective conditions when the $\mathrm{BL}$ increases. However, under conditions with weak convection the lidar data reveal higher values for the BLH. While the $\mathrm{BLH}_{\text {temp }}$ is mainly determined by the thermal conditions in the $\mathrm{BL}$, the microwave observations follow the evolution of the BL in the morning when thermal turbulence dominates. However, the $\mathrm{BLH}_{\text {aerosol }}$ does not always follow this evolution. $\mathrm{BLH}_{\mathrm{aerosol}}$ still gives the altitude of the aerosol layer formed at night, but in the afternoon, when the BL decreases, the aerosol concentrations are not diluted while mixing up with the surrounding air, leading to wrong values for the BLH. In the afternoon the BLH departs into a residual layer and a stable layer,

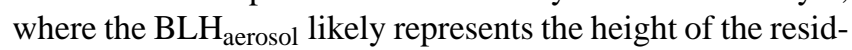
ual layer. Our observations show that both methods, lidar and microwave observations, give complementary results, that are both necessary to investigate properties of the boundary layer. Finally, overall our data agree with theoretical models.
Acknowledgements. The research is supported by the National Important Science Research Programme of China (2012CB955302) and the National Natural Science Foundation of China (41075104). We gratefully thank the Semi-Arid Climate Observatory and Laboratory of Lanzhou University providing observation data.

Edited by: A. Macke

\section{References}

Boers, R. and Eloranta, E. W.: Lidar measurements of the atmospheric entrainment zone and the potential temperature jump across the top of the mixed layer, Bound.-Lay. Meteorol., 34, 357-375, 1986.

Brooks, I.: Finding boundary layer top: application of a wavelet covariance transform to lidar backscatter profiles, J. Atmos. Ocean Tech., 20, 1092-1105, 2003.

Cohn, S. A. and Angevine, W. M.: Boundary layer height and entrainment zone thickness measured by lidars and wind-profiling radars, J. Appl. Meteor., 39, 1233-1247, 2000.

Davis, K. J., Gamage, N., Hagelberg, C. R., Kiemle, C., Lenschow, D. H., and Sullivan P. P.: An objective method for deriving atmospheric structure from airborne lidar observations, J. Atmos. Ocean Tech., 17, 1455-1468, 2000.

Emeis, S. and Schafer, K.: Remote sensing methods to investigate boundary-layer structures relevant to air pollution in cities, Bound.-Lay. Meteorol., 121, 377-385, 2006.

Emeis, S., Schaefer, K., and Muenkel, C.: Surface-based remote sensing of the mixing-layer height - a review, Meteorologische Z., 17, 621-630, 2008a.

Emeis, S., Schafer, K., and Munkel, C.: Long-term observations of the urban mixing-layer height with ceilometers, 14th international symposium for the advancement of boundary layer remote sensing, 2008b.

Emeis, S., Muenkel, C., Vogt, S., Mueller, W. J., and Schaefer, K.: Atmospheric boundary-layer structure from simultaneous SODAR, RASS, and ceilometer measurements, Atmos. Environ., 38, 273-286, 2004.

Flamant, C., Pelon, J., Flamant, P. H., and Durand, P.: Lidar determination of the entrainment zone thickness at the top of the unstable marine atmospheric boundary layer, Bound.-Lay. Meteorol., 83, 247-284, 1997.

Grabon, J. S., Davis, K. J., Kiemle, C., and Ehret, G.: Airborne lidar observatrions of the transition zone between the convective boundary layer and free atmosphere during the international $\mathrm{H}_{2} \mathrm{O}$ project (IHOP) in 2002, Bound.-Lay. Meteorol., 134, 6183, 2010.

Gryning, S. E. and Batchvarova, E.: Parameterization of the depth of the entrainment zone above the daytime mixed layer, Q. J. Roy. Meteor. Soc., 120, 47-58, 1994.

Haij, M. J. de, Wauden, W. M. F., and Baltink, H. K.: Determination of mixing layer height from ceilometer backscatter profiles, in: Proc. of SPIE vol. 6362 63620R, Remote Sensing of Clouds and the Atmosphere XI, Stockholm, Sweden, 11-12 September 2006, doi:10.1117/12.691050, 2006

Hooper, W. P. and Eloranta, E.: Lidar measurements of wind in the planetary boundary layer: the method, accuracy and results from joint measurements with radiosonde and kytoon, J. Clim. Appl. Meteor., 25, 990-1001, 1986. 
Holzworth, C. G.: Estimates of mean maximum mixing depths in the contiguous United states, Mon. Weather Re., 92, 235-242, 1964.

Lammert, A. and Boesenberg, J.: Determination of the convective boundary-layer height with laser remote sensing, Bound.-Lay. Meteorol., 119, 159-170, 2006.

Morille, Y., Haeffelin, M., Drobinski, P., and Pelon, J.: STRAT: an automated algorithm to retrieve the vertical structure of the atmosphere from single-channel lidar data, J. Atmos. Ocean. Tech., 24, 76-775, 2007.

Nelson, E., Stull, R. B., and Eloranta, E.: A prognostic relation for entrainment zone thickness, J. Appl. Meteor., 28, 885-903, 1989.

Seibert, P., Beyrich, F., Gryning, S.-E., Sylvain, J., Rasmussen, A., and Tercier, P.: Review and intercomparison of operational methods for the determination of the mixing height, Atmos. Environ., 34, 1001-1027, 2000.
Steyn, D., Baldi, M., and Hoff, R. M.: The detection of mixed layer depth and entrainment zone thickness from lidar backscatter profiles, J. Atmos. Ocean Tech., 16, 953-959, 1999.

Stull, R. B.: An Introduction to boundary Layer Meteorology, Kluwer Academic Publishers, Dordrecht/Boston/London, 1988.

Van Pul, W. A. J., Holtslag, A. A. M., and Swart, D. P. J.: A comparison of ABL heights inferred routinely from lidar and radiosondes at noontime, Bound.-Lay. Meteorol., 68, 173-191, 1994.

Wilde, N. P., Stull, R. B., and Eloranta, E. W.: The LCL zone and cumulus onset, J. Clim. Appl. Meteor., 24, 640-657, 1985.

Wiegner, M., Emeis, S., Freudenthaler, V., Heese, B., Junkermann, W., Muenkel, C., Schaefer, K., Seefeldner, M., and Vogt, S.: Mixing layer height over Munich, Germany: Variability and comparisons of different methodologies, J. Geophys. Res., 111, D13201, doi:10.1029/2005JD006593, 2006. 